\title{
Organizações não-governamentais como dispositivos de poder: do bem-estar ao controle social
}

\author{
Érika de Sousa Mendonça, ${ }^{I, \star}$ Jaileila de Araújo Menezes ${ }^{I I}$ \\ ${ }^{I}$ Universidade de Pernambuco, Pernambuco, PE, Brasil

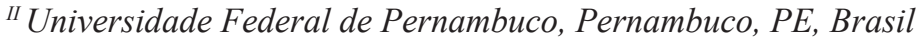

\begin{abstract}
Resumo
A partir de uma perspectiva da Psicologia Política e do referencial analítico foucaultiano, o estudo busca construir reflexões sobre Organizações Não-Governamentais voltadas ao público infanto-juvenil como dispositivos de poder. Para tanto - a partir de revisões bibliográficas e relatos de situações vivenciadas pela pesquisadora nesse tipo de instituição - localiza estratégias de poder identificadas com a a disciplina e a biopolítica, organizadas a partir de tecnologias e relações que controlam indivíduos e populações, tendo suas ações e posicionamentos justificados sob a lógica do governo do bem estar.
\end{abstract}

Palavras-chave: poder; organização não-governamental; dispositivo; controle; disciplina.

\section{Non-governmental organizations as power's devices: from welfare to social control}

\begin{abstract}
From a Political Psychology perspective and the Foucault's analytical referential, the study aims to build reflections about nongovernmental organizations focused on youth public as power devices. Therefore-from literature reviews and reports of situations experienced by the researcher in this kind of institution - locates strategies of power identified with the discipline and biopolitics, organized from technologies and relationships that control individuals and populations, having their actions and positions justified on the welfare government logic.
\end{abstract}

Keywords: power; non-governmental organization; device; control; discipline.

\section{Introdução}

As Organizações Não-Governamentais (ONGs) adentram no cenário brasileiro especialmente a partir da década de 1970. Por meio de alianças estabelecidas com grupos religiosos, voltam sua atenção ao acolhimento e assistência do público infanto-juvenil e à organização popular, em ações comprometidas com a conscientização e autonomia das classes menos favorecidas e a transformação social (LANDIM, 1998). Estas organizações surgem, ainda, como opositoras ao Estado, criticando-o e até assumindo parte de suas responsabilidades.

Todavia, para garantir sua existência e prosperidade, uma série de reconfigurações de suas estratégias de ação vai se desenhando, inclusive a partir de alianças com empresas privadas, com instituições internacionais e mesmo com o Estado. Público-alvo e focos de ação se ampliam e o cotidiano das ONGs sofre adaptações que incluem a submissão de projetos a órgãos financiadores e a necessidade de comprovação dos resultados de suas ações.

Assim é que as ONGs vão assumindo um caráter institucional com regras, padrões, metas a serem alcançadas e este cenário - destinado primariamente à atenção a crianças e jovens ditos em risco social e à conquista da autonomia de grupos populares - vai se tornando também um dispositivo de controle social. É nesse sentido que se configuram como um espaço profícuo de observação de tecnologias e jogos de poderes.

\footnotetext{
^Endereço para correspondência: Universidade de Pernambuco, Campus Garanhuns. Rua Cap. Pedro Rodrigues, 105 - São José, Garanhuns, PE - Brasil. CEP: 55294-902.E-mail: erika.mendonca@hotmail. com, jaileila.araujo@gmail.com
}

À luz dos estudos da analítica do poder de Michel Foucault, o estudo tem como objetivo problematizar o universo das Organizações Não-Governamentais voltadas ao público infanto-juvenil, analisando-as como dispositivos, buscando identificar em sua lógica de funcionamento estratégias do biopoder e tecnologias de controle social, que se justificam sob o argumento do bom governo e bem-estar da população. A partir de revisões bibliográficas e vivências profissionais de uma das autoras no contexto de ONGs, provocaremos reflexões sobre o tema.

\section{Organizações Não-Governamentais: considerações históricas e políticas}

De acordo com Danziato (1998), se retornarmos ao final do século XIX poderemos conferir que, com exceção dos estabelecimentos formais de ensino, as instituições públicas criadas destinavam-se às crianças e adolescentes que não correspondiam ao projeto higienista de esvaziamento do espaço público e de privatização do espaço familiar. $\mathrm{O}$ que se percebia eram tentativas de reordenação e disciplinarização em prol do ajustamento social, sobretudo, das camadas populares.

Para Priore (2012), o início do século XX é marcado, por um lado, pelo crescimento do número de entidades assistenciais voltadas ao atendimento de crianças órfãs, para a atenção aos abandonados e aos delinquentes e, por outro, é marcado por forte institucionalização da família nuclear das classes pobres, uma vez que suas crianças e adolescentes insistiam em se manter nas ruas, seja por não terem uma família nuclear sólida nos moldes da família burguesa, seja porque muitas vezes também precisavam se 
submeter a trabalhos que lhes garantissem sobrevivência. Assim é que crianças e adolescentes de classes populares tiveram, desde muito cedo, uma liberdade limitada - ou vigiada - seja na escola, nas ruas, em instituições religiosas ou pela sua apreensão em reformatórios, a partir de uma lógica supostamente protecionista, mas que parecia mais afim a uma estratégia política e econômica de dicotomia de classes sociais. Foi também nesse contexto - e pelos mesmos motivos - que foram criados órgãos nacionais de assistência como o Serviço de Assistência a Menores (SAM) em 1941 e a Fundação Nacional de Bem-Estar do Menor (FNABEM) em 1964.

Dentre as instituições religiosas, as Santas Casas de Misericórdia tiveram papel central na assistência a crianças, adolescentes e jovens pobres, principalmente a partir de 1940 com uma atuação mais partilhada entre a assistência hospitalar e a social, através da criação de Centros de Educação Infantil em todo o país. Podemos, contudo, estabelecer reflexões críticas sobre o papel por elas desenvolvido, refletindo se junto a um caráter filantrópico e protecionista não havia, também, um dispositivo institucional apontado para o reajustamento disciplinar da massa a que prestavam assistência.

Tais organizações, pela estreita aliança estabelecida entre sua ação beneficente e as práticas de assistência médica da medicina local, possibilitaram a transformação da filantropia de caráter caritativo (predominante em meados do século XIX) em um novo modelo de assistencialismo: a filantropia higiênica. Retirando velhos, meninos e meninas pobres das ruas em nome da erradicação da mendicância, da delinquência e prostituição urbanas, e internando-os em asilos onde realizava a disciplinarização moral e social por meio da catequese e do trabalho adestrador do corpo e da mente, esta filantropia higiênica institucionalizada teve, sem dúvida, decisiva participação no processo de normalização social (PONTES, 1993 apud DANZIATO, 1998, p. 36).

A partir de proposições assistencialistas, protecionistas e também disciplinadoras iniciaram-se, mais fortemente a partir da década de 1980, mobilizações políticas e sociais em prol de crianças e adolescentes de camadas popu8lares, como respostas a contextos de migração de famílias aos grandes centros urbanos, assim como dian888te de realidades como o trabalho e exploração infanto-juvenil e o aumento de moradores de ruas vivendo em situação de mendicância ou envolvidos em pequenos atos infracionais. Foi assim que o olhar e as consequentes ações sobre a infância e adolescência pobre se construíram, simultaneamente, entre um esforço protecionista e a busca pelo enquadramento da população mais jovem, a fim de que não resistisse à inserção num campo social já preestabelecido.

Especialmente no âmbito das organizações governamentais, por muito tempo não se conseguiu romper o modelo correcional, repressivo ou assistencialista. Ao mesmo tempo, contudo, fortaleciam-se movimentos da sociedade civil, experimentava-se uma profusão de organizações privadas no campo da assistência social aos menores e o Estado passava a retrair-se em suas funções protagonistas e solitárias.
É nesse contexto que surgem projetos com focos em ações educativas. Pautados no reconhecimento de crianças e adolescentes como sujeitos históricos, ações passam a ser privilegiadas na própria comunidade, ou seja, no contexto social daqueles que são assistidos ou "beneficiados" com esses projetos. Registram-se iniciativas que preveem a organização de meninos e meninas pobres para lutarem pelos seus direitos.

Esse momento é protagonizado especialmente pelas Organizações Não Governamentais (ONGs), que surgiram no Brasil da década de 1970, com o foco em evidenciar os "não-fazeres" do Estado, questionando-o. Estas entidades nasceram e se constituíram, todavia, em meio a conflitos identitários: são contrárias aos modos de ação do Estado, mas dependem de apoio Estatal; não são empresas, mas também atuam a partir de um ponto de partida que inclui missão, visão e valores; não visam o lucro, mas trabalham baseadas em metas verificáveis e seus lucros existem numa perspectiva da repercussão social de suas ações, sem a qual perdem a razão de existir.

Sobre as ONGs, Fernandes (FERNANDES; CARNEIRO, 1991, p. 07) assim as descreve:

Além de serem jovens, elas são relativamente estranhas no cenário institucional latino-americano. Manipulam somas vultosas, mas não visam o lucro. Mobilizam a dedicação voluntária, mas não são igrejas. Insistem na gratuidade do serviço, mas não são centros de filantropia. Mexem muito com política, mas não são partidárias e, via de regra, queremse distantes do Estado. Promovem o "desenvolvimento", mas não se especializam em "produtividade". Fazem pesquisas, mas não são acadêmicas. Não é fácil classificá-las.

Apesar dessas (in)definições sobre as Organizações Não-Governamentais, elas têm se mantido e garantido espaço social. Em agosto de 2011 foram apresentados dados de pesquisa desenvolvida a partir da parceria entre o Instituto Brasileiro de Geografia e Estatística (IBGE), o Instituto de Pesquisas Econômicas e Aplicadas (IPEA), a Associação Brasileira de Organizações Não Governamentais (ABONG) e o Grupo de Institutos, Fundações e Empresas (GIFE) sobre as Fundações e Associações Privadas Sem Fins Lucrativos no Brasil. A pesquisa demonstrou que existem em nosso país 338 mil organizações sem fins lucrativos, a maioria voltada para a área de assistência social (IBGE et al., 2012, par. 2).

Além de sua expressividade quantitativa, também a ação de ONGs tem sido reconhecida em contextos políticos e sociais. Atuando em redes, essas instituições organizam movimentos reivindicatórios nas ruas, adentram espaços culturais utilizando-se de recursos como o Teatro do Oprimido de Augusto Boal1 para provocar reflexões e inquietações nas comunidades, estão presentes em Assembléias e audiências públicas, produzem conhecimento e expressam críticas em meios midiáticos e não-midiáticos.

Assim é que, em parte, estas ONGs vêm para modificar o cenário, reconhecendo crianças e adolescentes como sujeitos de direitos, investindo em sua educação e

${ }^{1}$ Teatrólogo, fundador do "Teatro do Oprimido", uma técnica que alia o teatro à ação social, compreendendo-o não apenas como expressão artística, mas como instrumento de emancipação política. 
formação cidadã. Por outro lado, estas mesmas ONGs, ainda hoje, não reforçariam projetos sociais como recursos necessários à disciplinarização e socialização da parcela pobre da população, lançando seus familiares numa condição de impotência?

$\mathrm{Na}$ tentativa de ofertar melhores condições às crianças e adolescentes a que acolhem, estas organizações tendem a agir segundo seus próprios princípios isentando-se, muitas vezes, de reflexões sobre o quanto esta ou aquela prática é ressonante com desejos e interesses das comunidades em que atuam. E nesta configuração, questionamos: que tecnologias e modos de expressão de poder são mobilizadas pelas ONGs para elas mesmas sobreviverem?

\section{Poder e dispositivo na obra foucaultiana: aproximações teóricas}

Nas ciências humanas e sociais, aí incluindo-se a Psicologia, ao pensarmos o tema do poder, um dos autores mais fortemente relacionados é Michel Foucault, já que sua vasta produção acadêmica inclui reflexões sobre contextos, formas, mecanismos de poder. Apesar desta referência, uma teoria do poder jamais foi publicada pelo filósofo.

Embora sem uma definição ou teorização sobre o poder, este é discutido como uma rede de dispositivos ou mecanismos que é relacional, exerce-se e não está concentrado no Estado, mas também em instituições, pessoas e contextos, e que demarca modos de subjetivação entre os envolvidos (MACHADO, 1979).

Em seu livro Vigiar e punir, ao construir uma análise sobre a legislação penal e o sistema punitivo adotado pelos poderes jurídicos frente à criminalidade e à delinquência ao longo dos séculos, Foucault (2011) introduz reflexões sobre dois mecanismos de poder: o poder de soberania e o poder disciplinar.

No poder de soberania, a gestão da vida tem como um dos atributos fundamentais a decisão sobre a vida ou a morte do outro, ao que Foucault chama "deixar viver e fazer morrer". Nesse sentido, quando os indivíduos se reúnem para constituir um soberano, eles o fazem no intuito de proteger a própria vida, pois a vida e a morte dos súditos só se tornam direitos pelo efeito da vontade soberana (FOUCAULT, 2010a).

Outra característica do governo de soberania é que o bem comum vai existir quando todos os sujeitos obedecerem às leis, quando exercerem bem seus cargos e ofícios. Assim é que o bem público é reflexo, essencialmente, da obediência à lei do soberano. Essa circularidade põe a lei e a soberania como sendo um só corpo: a soberania retira seus instrumentos dela própria sob a forma da lei. Este poder é, então, explícito e marcado em si mesmo. Explícitas também são as punições neste modo de poder: estas incluem sempre a espetacularização, a exposição pública da pena. O poder sobre a vida e a morte dos súditos é ritualizado e visibilizado na soberania.

Entretanto, a partir de contextos como a explosão demográfica, o poder político do soberano de matar lenta e publicamente milhares de pessoas vai se tornando dispendioso. Também a cerimônia ritualística e violenta das mortes em locais públicos põe em risco o poder do soberano, pois a possibilidade de revolta começa a se esboçar. Mas, principalmente, o processo de industrialização com a necessidade de corpos economicamente úteis faz emergir uma nova configuração: o poder disciplinar.

Como o próprio nome sugere, este é baseado na disciplina e na normalização de condutas e comportamentos. Mas essa vigilância se dá nos pormenores. Há um esquadrinhamento do tempo, do espaço e dos movimentos dos corpos individualizados: "Não se trata de cuidar do corpo em massa, grosso modo, como se fosse uma unidade indissociável, mas de trabalhá-lo detalhadamente; de exercer sobre ele uma coerção sem folga, de mantê-lo ao mesmo nível da mecânica" (FOUCAULT, 2011, p. 132-133).

Esse controle minucioso das disciplinas tem como fim a sujeição dos corpos e uma relação de docilidade-utilidade, a fim de que se produzam corpos úteis política e economicamente. É importante destacar, todavia, que suas características o distanciam de noções como escravização, domesticidade, vassalidade ou ascetismo, pois não há apropriação desses corpos nem seu fim é a submissão a outrem. O objetivo que se almeja é o aumento do domínio de cada um sobre si, sobre seu corpo, aumentando-lhe suas habilidades e tornando estes corpos tanto mais obedientes quanto úteis.

Essa mecânica do poder que caracteriza a disciplina tem fins econômicos, políticos e também traz suas próprias sanções. A visibilidade não deixa de existir, mas agora ela é feita no espaço interno, onde os bons comportamentos são recompensados e os maus, punidos. Na disciplina, através de sujeições dos corpos, dociliza-se também a alma: as tecnologias disciplinadoras evitam mecanismos de resistência da população, que acaba por sucumbir, muitas vezes, às ordens superiores.

Mas diante de fenômenos e problemas próprios à população, o controle sobre ela também se faz necessário. As estatísticas descobrem e demonstram que, através de seus modos de agir, através de suas atividades, a população gera efeitos econômicos específicos e se faz necessário também controlá-la enquanto espécie e não apenas enquanto sujeitos isolados. O olhar e as ações, nesse sentido, não se dirigem mais ao homem-corpo, mas ao homem ser-vivo, ao homem-espécie, segundo o referido autor.

A biopolítica, então, instaura-se como tecnologia de poder mapeando e controlando fenômenos populacionais como natalidade, mortalidade, longevidade, identificando e tratando endemias, sua natureza, extensão, duração, como reflete Foucault (2010a). É a natureza dos fenômenos que é levada em consideração: fenômenos coletivos que só aparecem com seus efeitos econômicos e políticos e que só se tornam pertinentes no nível da massa. A população aparece como objetivo último do governo que se volta a melhorar o seu destino com o intuito de aumentar riquezas. Assim é que introduz-se uma medicina cuja maior função é de higiene pública e garantia de extensão da vida.

No contexto da biopolítica, identificamos a governamentalidade como um regime estratégico utilizado pelo Estado para garantir o controle das populações em torno 
dos objetivos de economia política. Foucault (2010b, p. 303) assim a define: "O conjunto constituído pelas instituições, procedimentos, análises e reflexões, cálculos e táticas que [...] tem como alvo a população, tem como forma mais importante de saber a economia política e como instrumento técnico-essencial os dispositivos de segurança". Mas a estratégia da governamentalidade seria utilizada apenas pelo Estado? Ou suas estratégias estão disseminadas em outras instituições que também contribuem para o controle e enquadramento das populações?

Instituições de assistência, por exemplo, também ganham relevância na biopolítica. Já identificamos sua existência desde o início do século XIX, especialmente articuladas a organizações religiosas. Mas agora o controle se dá por meio de "mecanismos muito mais sutis, economicamente muito mais racionais do que a grande assistência [...] vamos ter mecanismos mais sutis, mais racionais, de seguros, de poupança individual e coletiva, de seguridade, etc.” (FOUCAULT, 2010a, p. 205). Poderíamos identificar as Organizações Não-Governamentais como instituições que ajudam, na minúcia das proposições e atos, a promover o controle das populações?

Refletir sobre a possibilidade do papel institucional das ONGs no controle e regulamentação das populações é pensar no conceito de dispositivo tratado por autores como Deleuze, Foucault e Agamben (AGAMBEN, 2005). O dispositivo, tal como discutido por estes filósofos, não se refere ao poder exercido por uma instituição, mas por uma rede, por um conjunto heterogêneo que inclui elementos linguísticos e não-linguísticos, discursos, instituições, leis, medidas de segurança, tendo como função estratégica o estabelecimento de relações de poder.

Agamben (2005) busca no pensamento foucaultiano as raízes do termo dispositivo. Neste resgate histórico, indica que o termo anteriormente usado por Foucault era "positividade" (termo tomado emprestado de seu professor Hyppolite), sendo este definido por aquilo que representa obstáculos à liberdade humana. Assim reflete:

"Positividade" é [...] o elemento histórico, com toda a sua carga de regras, ritos e instituições impostas aos indivíduos por um poder externo, mas que se torna, por assim dizer, interiorizada nos sistemas das crenças e dos sentimentos, então Foucault, tomando emprestado este termo (que se tornará mais tarde "dispositivo") toma posição em relação a um problema decisivo, que é também o seu problema mais próprio: a relação entre os indivíduos como seres viventes e o elemento histórico, entendendo com este termo o conjunto das instituições, dos processos de subjetivação e das regras em que se concretizam as relações de poder (AGAMBEN, 2005, p. 10-11).

Assim, entendemos que os dispositivos não correspondem a uma ou outra tecnologia de poder, mas envolvem uma série de práticas e mecanismos que intervém de algum modo na vida da população e que se enraízam em seus sistemas de crenças. Dispositivos compreendem uma rede de elementos que controlam, asseguram gestos, condutas e discursos, por meio de instituições, medidas jurídicas e elementos linguísticos com o suposto objetivo de governar a população e guiá-la para o bem.
Sob essa linha argumentativa, não há vida sem dispositivos, pois de algum modo somos todos guiados, modelados ou controlados em alguma direção, mesmo que não percebamos tais condutas. Para Agamben (2005, p. 13): "Os dispositivos não são um acidente no qual os homens caíram por acaso, mas eles têm a sua raiz no mesmo processo de 'hominizacão' que tornou 'humanos' os animais que classificamos sob a rubrica homo sapiens".

Se olharmos novamente para as ONGs voltadas à promoção da cidadania e socialização de crianças e adolescentes pobres estaremos, então, diante de uma instituição que se configura como um dispositivo regulamentador de hábitos, posturas e comportamentos, seja atuando por modos mais individualizantes e disciplinadores ou mais numa perspectiva de biopolítica e controle da massa, do corpo-espécie, da população.

A questão que se põe é: provavelmente, estas instituições não pensam o lugar que ocupam sob esse prisma, mas se posicionam como organizações preocupadas com o bem-estar de crianças e adolescentes, com pouca reflexão sobre o status de poder que ocupam e sobre as práticas de governança que exercem junto à população e à comunidade na qual atuam. Todavia, ao não problematizarem sua própria condição de dispositivo de poder e suas ações e contradições nesse processo, não estariam se distanciando da possibilidade de virem a concretizar seu discurso de engajamento e protagonismo social?

\section{ONGs como dispositivos: olhares sobre relações e tecnologias de poder e controle de populações}

Ao longo dos seus estudos de genealogia, Foucault destrincha três modalidades de exercício do poder: o poder de soberania, o disciplinar e a biopolítica. O autor indica contextos históricos, políticos e sociais que justificavam a eminência de um outro (novo) sistema de poder, mas também advoga que nenhuma destas formas tenha deixado de existir e particularmente a partir do século XVIII elas passam a se sobrepor. Há um tripé soberania-disciplina-biopolítica cujo alvo principal é a população e os mecanismos essenciais são os dispositivos de segurança. Nas palavras de Foucault (2010b, p. 302):

Todavia, nunca, tampouco, a disciplina foi mais importante e mais valorizada do que a partir do momento em que se tentava gerir a população. Gerir a população não quer dizer gerir simplesmente a massa coletiva dos fenômenos ou geri-los simplesmente no nível de seus resultados globais. Gerir a população quer dizer geri-la igualmente em profundidade, em fineza e no detalhe [...] é preciso compreender as coisas não como a substituição de uma sociedade de soberania por uma sociedade de disciplina e depois por uma sociedade, digamos, do governo.

É com base nesse tripé - a que chamaremos biopoder - que seguirão nossas reflexões, tendo-se escolhido Organizações Não-Governamentais como cenário privilegiado para a observação da manifestação desses poderes. A escolha por este cenário é pautada em dois pontos principais: 1) considerando-se aspectos históricos de instalação das ONGs no Brasil - como apresentado anteriormente - bem como compreendendo suas novas con- 
figurações, percebemos essas instituições como centro de contradições e jogos de tensão, poder e controle internos e externos; 2) leva em conta um acúmulo de vivências de uma das autoras em contextos de ONGs e sua experiência profissional como educadora e como pesquisadora, com observações e inquietações daí elencadas também no que se refere a jogos e tecnologias de poder.

Embora tentemos identificar matrizes de um ou outro tipo de poder, enfatizamos, uma vez mais, nossa compreensão de que estes poderes estão entrelaçados, com alguma característica se destacando, mas todos fazendo parte de uma só rede de ação chamada biopoder e exercida pelos mais diversos dispositivos.

Traremos, aqui, a título de ilustração, situações com as quais nos deparamos em trabalhos anteriores vivenciados no contexto de três Organizações Não-Governamentais atuantes na cidade do Recife-PE e região metropolitana. 2

Começaremos por refletir sobre como se justifica a produção de projetos sociais para financiamento de ações de uma ONG que tem como missão a proteção social e formação complementar de crianças e adolescentes de comunidades populares. Trata-se de uma $\mathrm{ONG}$ que à época da observação tinha 14 anos de existência e ofertava atendimento diário por meio de atividades grupais com cunho artístico, educativo e terapêutico a meninas com idades entre 07 e 17 anos.

O primeiro passo dado pela organização ao se lançar na escrita de novos projetos estava em perceber necessidades e carências naquele espaço comunitário que precisavam ser superadas ou melhoradas. Este mapeamento de território ocorria por meio de observações no próprio local ou avaliando-se dados sócio-econômicos da região. Mas para ser implantado um projeto, necessariamente se impunha uma fundamentação baseada em tais dados. Isso se dava porque as informações precisavam ser quantificadas e comprovadas, era necessário que se provassem necessidades da população. Neste contexto, hoje, identificamos o papel das estatísticas, dos institutos de pesquisa, dos dados que constroem indicadores como o Índice de Desenvolvimento Humano populacional (IDH), levantado e divulgado anualmente nos municípios.

Através do IDH são identificadas carências e/ou deficiências de dada população e, assim, ficam devidamente justificadas as linhas de ação a serem empreendidas por projetos sociais. Tudo isso com o foco na população, a fim de contribuir para que esta se desenvolva de modo sadio e próspero, tornando-se força economicamente ativa.

Foco na população, dados estatísticos, localização de problemáticas coletivas: não estaríamos tratando de biopolítica e de controle coletivo, justificados sob o viés do benefício da massa? Sim, estamos diante de uma tecnologia que é centrada em efeitos produzidos e voltados a uma população: "uma tecnologia que procura controlar a série de eventos fortuitos que podem ocorrer numa massa viva, que procura controlar (eventualmente modificar) a proba-

${ }^{2}$ Os nomes das ONGs de onde partem essas observações serão mantidos em sigilo, revelando uma atitude ética de preservação da identidade da instituição. bilidade desses eventos, em todo caso em compensar seus efeitos" (FOUCAULT, 2010a, p. 209). O foco, assim, é na segurança do conjunto em relação a seus próprios perigos.

Mas ainda num olhar aos índices pensando-se nos índices sociais de saúde ou de educação que são levantados e apresentados como suporte ou ênfase à argumentação das necessidades de dada comunidade, passemos agora a observar um cenário em que os dados estatísticos, uma vez levantados, são codificados em linguagens e informações que atendam aos editais - lançados por empresas privadas ou o Estado - com fins de apoiar projetos sociais.

A segunda Organização Não-Governamental sobre a qual retomaremos algumas das experiências vivenciadas, voltava-se ao público infantil e atuava há sete anos na cidade do Recife-PE. Tinha na educação artística sua estratégia de inserção social de crianças por eles consideradas "em situação de risco social". Trabalhava a partir de expressões artísticas como a dança e a música no intuito de transmitir valores de auto-cuidado, de contribuir com o fortalecimento da auto-estima, promovendo apresentações artístico-culturais públicas na própria comunidade, valorizando-a. Esta era a linha de ação explicitada em sua "visão" e "missão" de trabalho. Mas eis que uma instituição privada divulga um edital para o financiamento de ações voltadas à prevenção de doenças sexualmente transmissíveis (DSTs) e gravidez precoce.

Educação artística e prevenção a DSTs e gravidez: propostas e diretrizes divergentes? Não necessariamente. Adaptam-se (ou criam-se) necessidades, forjam-se saberes e, enfim, submetem-se projetos com a finalidade pretendida pelo órgão financiador, mesmo quando este não é o foco de atuação da ONG. A justificativa está em que qualquer ação que se promova junto à população, será benéfica a eles. Nesse sentido, questionamos: quem decide quais são as necessidades da comunidade?

Porque se de um lado temos indicadores reais que apontam investimentos político-sociais necessários à população, do outro lado temos um jogo de moralidades e valores até mesmo religiosos que são impostos à população, seja através da educação formal de escolas, seja através de programas e projetos sociais de iniciativa pública ou privada que julgam gerar benefícios à população. Ao refletir sobre as sociedades contemporâneas e suas constituições políticas, Hardt e Negri (2001) discutem as ONGs como fazendo parte da nova ordem biopolítica em que as intervenções morais se fazem presentes, atuando como tecnologias de controle social.

E este olhar não pode ser deixado de lado sob o risco de ficarmos na inocência pura sobre as boas intenções da atuação destas organizações, embora as reconheçamos. Há que se perceber, também, os jogos de poder e as tecnologias sociais de controle que operam nas ONGs. Nas palavras de Hardt e Negri (2001, p. 54):

De fato, os poderes imperiais de intervenção podem ser mais bem entendidos como algo que começa não diretamente com armas de força letal, mas com instrumentos morais. O que chamamos de intervenção moral é praticado hoje por uma variedade de entidades, incluindo os meios 
de comunicação e organizações religiosas, mas as mais importantes talvez sejam as chamadas organizações não-governamentais (ONGs), as quais, justamente por não serem diretamente administradas por governos, entende-se que agem a partir de imperativos éticos ou morais.

Sob um olhar mais atento, ao localizar e buscar sanar deficiências, ao agir sob a égide da moralidade, ONGs também podem ter sua atuação identificada a partir de estratégias disciplinadoras com fins produtivos. Numa análise sobre o cotidiano de ação da referida $\mathrm{ONG}$, identificamos como força propulsora uma perspectiva socializadora,3 preparando crianças para um melhor convívio social, vislumbrando futura entrada no mundo adulto e no mercado de trabalho.

Com esse propósito, eram desenvolvidas atividades de formação complementar que incluíam regras de boa convivência, boas maneiras, sendo incentivados bons hábitos e apresentados novos gostos culturais. Ampliava-se o ensino da educação básica e oferecia-se formação complementar com introdução artística, esportiva e cidadã, inclusive pensando-se na arte como ferramenta futura de trabalho, numa ação em consonância com as expectativas mercadológicas de um contexto capitalista. Numa análise mais profunda, compreendemos que se produzem, nestes contextos, corpos economicamente úteis e politicamente dóceis. Mas como essas ações são empreendidas?

Ao mesmo tempo em que ONGs podem funcionar como máquinas de ensino, podem também atuar como espaços de vigilância, de controle, de recompensas, logo como dispositivos de governamentalidade com condução de condutas. Elas marcam lugares e indicam valores e sua organização pode assegurar tanto a obediência dos indivíduos, como uma melhor economia do tempo das atividades ali empreendidas, além de uma regulação dos gestos de acordo com valores pré-estabelecidos, tal como ocorre no poder disciplinar (FOUCAULT, 2011). Ao atuarem nesse sentido, uma ação com potencial lúdico e/ou estético, acopla-se com investimentos de modelagem de corpos a partir de fins econômicos, por meio de uma adequação do indivíduo a valores e ritmos sociais desejados.

Simultaneamente ao foco na produção de corpos economicamente úteis, busca-se também a formação de indivíduos politicamente dóceis. $\mathrm{O}$ controle das atividades que Foucault referia na sociedade disciplinar pode também ser vislumbrado na rotina das ONGs (e esta observação se dá a partir da vivência junto às três diferentes ONGs a que nos vinculamos: estabelecimento de horários, determinação de ocupações e a criação de ciclos de repetição, tudo isso assegurando uma rotina a ser cumprida. Esta rítmica do tempo deve assegurar a qualidade das ações e preparar o corpo da criança ou do jovem participante da ONG. Também aí localizamos a elaboração temporal do ato com programações e organizações precisas que lembram o esquema anátomo-cronológico

\footnotetext{
Assumimos, aqui, o sentido de socialização defendido por Berger e Luckmann (1985), entendendo a socialização como um processo de absorção de submundos institucionalizados feitos pelas crianças, a partir de ensinamentos e valores transmitidos pelos pais ou cuidadores, que lhes garantirão uma inserção e adaptação ao mundo social.
}

do comportamento refletido por Foucault (2011, p. 147) nos estudos sobre as prisões, segundo o qual "um corpo disciplinado é a base de um gesto eficiente".

Buscando-se rendimentos ótimos e avanços nos aprendizados e posturas de crianças e adolescentes, repetem-se regras e condições para "viver uma vida boa": tem que estudar, se dedicar, se comportar, saber usar o próprio tempo com a máxima eficiência e qualidade, buscando os rendimentos ótimos que assegurem ao futuro adulto uma boa entrada no mundo político-econômico.

Tais ordenamentos em si já apresentam o potencial de docilização de corpos, mas este movimento fica ainda mais evidente se considerados os sentimentos de gratidão expressos pela população assistida aos educadores e gestores de ONGs, haja vista os benefícios recebidos. A gratidão explicitada pela comunidade frente às oportunidades que estas instituições empreendem na vida de suas crianças e adolescentes não passa despercebida. Educadores e gestores das ONGs são respeitados e admirados na comunidade em que atuam. Até mesmo o uso de roupas pelos educadores, com a identificação da organização em que trabalham, configura-se como um instrumento que permite andar livremente pela comunidade sem riscos, pois aquelas são vistas como pessoas que ajudam seus moradores.

Outra situação que demonstra esse agradecimento da população está nos registros de uma publicação feita após a realização de dado projeto social ligado a uma ONG (MENDONÇA, 2010). Nesta publicação, foram colhidas declarações de crianças, adolescentes e familiares sobre o projeto então executado. As declarações de agradecimentos à instituição e aos educadores chamaram a atenção, sendo o mote principal de suas falas.

Uma última consideração nesse percurso analítico do universo das ONGs sobre relações de poder ainda se faz necessário. Após tecermos reflexões sobre o momento da construção e execução de um projeto social ou linha de ação de uma ONG, após observarmos o biopoder em atuação, discutamos agora sobre a finalização de dado projeto social mantido por meio de editais de empresas privadas ou do Estado.

Para obter êxito nesses editais, um projeto é submetido a avaliações. Uma vez que receba e faça uso dos recursos financeiros do órgão investidor, é preciso também que se prestem contas dos resultados alcançados. Nestes instantes, novamente contamos com os resultados estatísticos, com indicadores quantitativos que demonstram impactos positivos na população assistida, remetendo-nos ao contexto da biopolítica.

E esses resultados - não apenas os quantitativos, mas também os qualitativos - precisam ganhar visibilidade para além da instituição ou mesmo da comunidade em que atuam. Além dos quadros e dados estatísticos, o registro de fotografias, vídeos, imagens que demonstrem mudanças na população precisam ser disponibilizados e expostos, a fim de divulgar uma tal "empresa-cidadã" ou uma ação social realizada pelo governo X. 
Essa necessidade de visibilidade foi percebida mais especificamente no contexto de uma terceira ONG em que atuamos, esta que surgiu como projeto social de um Shopping Center, portanto, financiada por empresários que necessitavam ver, reconhecer e divulgar os resultados dos próprios investimentos.

A exposição dos resultados e dos corpos úteis e docilizados se dá por meio de rituais como festivais de arte $\mathrm{e}$ cultura, ou exposições de artefatos e produtos construídos pelas crianças e adolescentes. Pessoas e histórias de vida, tratadas e retratadas como corpos individualizados, viram também dados e indicadores de sucesso, massificados, como imagens de uma intervenção positiva, como ações de um governo de bem estar junto a uma população.

\section{Reflexões finais}

Apresentamos os dispositivos como uma rede de elementos que controlam, que asseguram gestos, condutas e discursos, que atuam no suposto intuito de governar a população e guiá-la para o bem. Como uma rede, os dispositivos são formados por diferentes elementos, pessoas, instituições e, pelo discutido, não nos restam dúvidas de que as Organizações Não-Governamentais constituem-se como parte deste enredamento. ONGs, em nossa análise, configuram-se como um dispositivo que faz uso de distintas tecnologias para estabelecer relações de poder.

Na lógica do biopoder, experimentamos uma realidade que Foucault (2010a) tratou como a política do "fazer viver e deixar morrer". No biopoder, são implantados mecanismos reguladores que vão focar na maximização das forças e da vida, para que também o máximo possa ser extraído dela. É o fazer viver que importa. É preciso, então, buscar o equilíbrio global, a segurança do coletivo em relação aos seus perigos internos. É preciso que se realizem controles de natalidade e da própria sexualidade; é preciso o controle sobre o uso de drogas e tudo aquilo que faz mal à saúde. É necessário que se aprendam ofícios e bons modos para que uma adequada inserção no mercado de trabalho se realize. É importante, enfim, uma população saudável e economicamente ativa, e esse controle, também identificado nas ONGs, só se dá por meio de uma atuação nos níveis micro e macro, do indivíduo e da população. É nessa expansão da vida - mas de uma vida controlada - que localizamos o "fazer viver" próprio do biopoder.

Nossa inquietação, então, nesse estudo, esteve na realização de uma análise política e institucional junto à Organizações Não-Governamentais voltadas ao público infanto-juvenil, a fim de problematizar matrizes e tecnologias de poder que as constituem e definem, também, como dispositivo de controle social, a partir da "boa condução de condutas".

Sob a justificativa de formação de cidadãos, sob a égide da promoção de movimentos socializadores e ressocializadores, ONGs e outras tantas instituições empreendem suas ações. No governo do bem-estar das populações, fazem uso de tecnologias de proteção, de formação ampliada e preparo para a vida pública, mas também se instrumentalizam de tecnologias disciplinares, de controle e de vigilância. E nesse contexto, ques- tionamos: está-se mais preocupado com a formação de crianças e jovens cidadãos, autônomos, protagonistas e capazes do cuidado de si ou o foco está na construção de crianças e jovens socialmente ajustados e controlados?

Não temos dúvidas de que benefícios possam ser gerados na população-alvo das Organizações Não-Governamentais, não é isso que discutimos aqui. Nosso foco está em identificar lógicas de poderes que precisam ser questionados em organizações que se propõem de vanguarda. São as contradições que evidenciamos. Focamos nas ONGs como dispositivos que, simultaneamente, protegem e controlam.

Consideramos, por fim, que tratar de poder é tratar de relação: o poder só existe em relação a um outro, e este outro não é alguém pacífico que sofre sob o poder do mais forte (a isso denominamos subordinação). Entendemos que o poder não está demarcado em uma pessoa ou instituição, mas ele pressupõe a relação entre indivíduos ativos que exercem o poder um sobre o outro. Movimentos de resistências, de construções e posicionamentos subjetivantes são, então, parte constitutiva do que chamamos poder. Esses movimentos, contudo, não foram abordadas neste artigo, embora sua presença seja reconhecida e valorizada, afinal é da relação entre sujeitos - gestores, educadores, crianças, jovens, familiares - que estamos tratando. Ações de resistência protagonizadas por crianças e jovens no contexto de ação das Organizações Não-Governamentais serão alvos de estudos futuros.

Para a Psicologia Política, que tem como um dos seus focos a implicação na busca por transformações políticas e pela emancipação dos sujeitos, acreditamos ser este estudo relevante por evidenciar jogos e tecnologias disponibilizadas no cotidiano de ação de projetos sociais dos quais, por vezes, até os próprios psicólogos se vêem fazendo parte. Numa compreensão foucaultiana, entendemos as relações de poder como inerentes às relações humanas, mas suas configurações - mais sutis ou mais explícitas - no contexto institucional, também precisam ser alvo de análise e intervenção, precisam ser mote de interesse da Psicologia Política como campo de problematização dos conflitos, antagonismos e agonismos sociais e como instrumento de intervenção psicossocial capaz de transformar realidades em prol da justiça social.

\section{Referências}

AGAMBEN, G. O que é um dispositivo? Outra Travessia, Florianópolis, n. 5, p. 9-16. 2005. Disponível em: $\quad<$ https://periodicos.ufsc.br/index.php/Outra/article/ view/12576/11743>. Acesso em: 12 dez. 2014.

BERGER, P.; LUCKMANN, T. A construção social da realidade. Petrópolis, RJ: Vozes, 1985.

DANZIATO, O. ONG's e a prática social com adolescentes: demarcações históricas e discursivas. Ijuí, RS: Unijuí, 1998.

FERNANDES, R.; CARNEIRO, L. Ong's anos 90: a opinião dos dirigentes brasileiros. Fortaleza: Núcleo de Pesquisa ISER, 1991. Mimeografado.

FOUCAULT, M. Em defesa da sociedade: curso no Collège de France (1975-1976). São Paulo: Martins Fontes, 2010a.

Fractal, Rev. Psicol., v. 29 - n. 3, p. 272-279, 2017 
FOUCAULT, M. Estratégia, poder-saber. Rio de Janeiro: Forense Universitária, 2010b. Coleção Ditos \& Escritos, v. 4.

FOUCAULT, M. Vigiar e punir: história da violência nas prisões. Petrópolis, RJ: Vozes, 2011.

HARDT, M.; NEGRI, A. Império. Rio de Janeiro: Record, 2001.

INSTITUTO BRASILEIRO DE GEOGRAFIA E ESTATÍSTICA et al. FASFIL 2005: números e dados das Fundações e Associações Privadas Sem Fins Lucrativos no Brasil (FASFIL). Disponível em: <http://www.abong.org.br/ lutas_e_acoes.php?id=3474\&it=5939>. Acesso em: 2 dez. 2016.

LANDIM, L. (Org.). Ações em sociedade: militância, caridade, assistência, etc. Rio de Janeiro: NAU, 1998.

MACHADO, R. (Org. e trad.). Introdução: por uma genealogia do poder. In: FOUCAULT, M. Microfisica do poder. Rio de Janeiro: Graal, 1979. p. VII-XXIII.

MENDONÇA, É. Agora eu sei! Diálogos sobre idéias que se realizaram. Olinda: Livro Rápido, 2010.

PRIORE, M. A criança negra no Brasil. In: JACÓ-VILELA, A.; SATO, L. (Org.). Diálogos em Psicologia Social [online]. Rio de Janeiro: Centro Edelstein de Pesquisas Sociais, 2012. p. 232-253. Cross ${ }^{\text {Ref. }}$

Recebido em: 23 de fevereiro de 2015 Aceito em: 7 de abril de 2017 